\title{
Neutrophil Lymphocyte Ratio in Prediction of Hepatocellular Carcinoma in Egyptian Patients with Chronic Hepatitis C
}

\author{
Hany R. Shabana ${ }^{1}$, Abd-Elmohsen E. El-Desoky ${ }^{2}$, Marwa S. Askar ${ }^{3}$ \\ Specialized Medical Hospital, Faculty of Medicine, Mansoura University, Mansoura, Egypt \\ Aga Hospital, Ministry of Health, Dakahlia, Egypt
}

\section{Introduction}

In Egypt, hepatocellular carcinoma (HCC) is a national health problem. It is now the first cause of cancer related mortality (1).This is mainly attributed to the heavy burden of chronic hepatitis C (CHC)virus infection(14.7\%), which leads to liver cirrhosis in approximately $20 \%$ of patients within 20 years of infection. Among cirrhotic patients, $1-4 \%$ will develop HCC every year (2).

It is well known that the diagnosis of HCC at early stages allows the application of curative therapies like surgery and thermal ablation. This can be reached through the application of the surveillance program to high risk populations.

In recent years, accumulating evidence showsthat increased systemic inflammation is associated with poor cancer-specific survival in a variety of cancers (3-4). These studies revealed that the host's inflammatory response to cancer and/or the systemic effects exerted by the cancer cells leads to upregulation of the inflammatory process(5-6). The presence of a systemic inflammatory response can be detected by both the elevation of the C-reactive protein (CRP) level (7) and neutrophil-lymphocyte ratio (NLR) (8). Neutrophils and other cells such as macrophages have been reported to secrete tumor growth promoting factors, including vascular endothelial growth factor (9-10), hepatocyte growth factor (11), IL-6 (12), IL-8 (13), matrix metalloproteinases (14) and elastases (15), and thus likely contribute to a stimulating tumor microenvironment. Neutrophilia as an inflammatory response inhibits the immune system by suppressing the cytolytic activity of immune cells such as lymphocytes, activated $\mathrm{T}$ cells, and natural killer cells (16-17).Thus, NLR reflects an immune microenvironment that favors tumor vascular invasion and suppresses the host immune surveillance.

\section{Aim of the Work}

The aim of this work is to examine the utilityof neutrophil lymphocyte ratio in predicting the occurrence of HCC in chronic HCV Egyptian patients.

\section{Patients and Method}

This study was conducted in Specialized Medical Hospital, Mansoura University in the period from January2014 to December2015.It included 111 adult patients (100 males, 11 females) with CHC and untreated HCC (group I) and 222 adult patients (128 males,94 females)with CHC without HCC (group II). CHC was diagnosed by ELISA for HCV antibody and confirmed by quantitative serum HCV RNA .HCC diagnosis was based on EASL criteria (18) i.e. focal hepatic lesion characterized by arterial phase enhancement and washout in portal and delayed phases, obtained by contrast enhanced abdominal CT and or MRI. NLR is derived from absolute neutrophil and absolute lymphocyte counts of the full blood count, provided that there was no ongoing bacterial infection at the time of blood sampling. Routine work up was done for all patients including liver and renal biochemical tests. We computed receiver operating characteristic (ROC) curve for NLR concerning HCC occurrence. We also calculated stratum specific likelihood ratios (SSLR) of NLR in relation to HCC. SSLR was calculated as the proportion of diseased subjects with a test result in a given range (group I) divided by the proportion of non-diseased subjects (group II) with a test result in the same range. We used the percentiles method for calculation of the SSLR as follows (19):

Step 1. Establish the strata and tabulate the stratum specific test results.

Step 2. Compute proportion of patients with the disease with that results.

Step 3. Compute proportion of patients without the disease with that results.

Step 4. Divide the fractions with the disease by the fractions without the disease.

Step 5. Calculate confidence intervals.

\section{Results}

Baseline tumor and patients characteristics are shown in figure (1) and table (1).NLR was significantly higher in group Ithan group II .It was $2.56 \pm 1.31$ in group I versus $1.75 \pm .91$ in group II ( $\mathrm{P} \leq 000$ ). The cut off value of NLR above which there was a high risk of HCC occurrence was $\geq 2.015$. Area under the curve (AUC) was 70.5\%, sensitivity was $60.7 \%$, specificity was $71.7 \%$, positive predictive value of $55.1 \%$, 


\section{International Journal of Science and Research (IJSR) \\ ISSN (Online): 2319-7064 \\ Index Copernicus Value (2013): 6.14 | Impact Factor (2014): 5.611}

negativepredictive value of $76.1 \%$, accuracy of $67.7 \%$ and positive likelihood ratio of 2.14 (figure2). The SSLR for HCC presence by NLR was 0.54 if NLR was $<2,1.74$ if NLR was2 to 4 and 7.14 if NLR was $>4$.
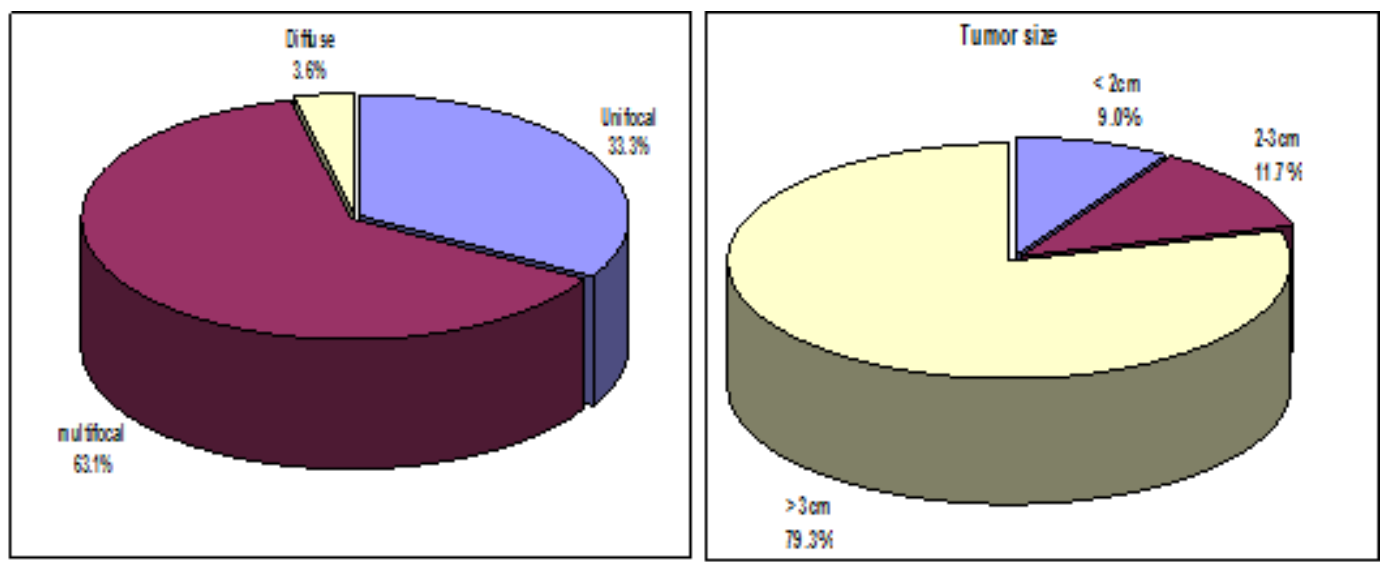

Figure 1: Baseline tumor characteristics

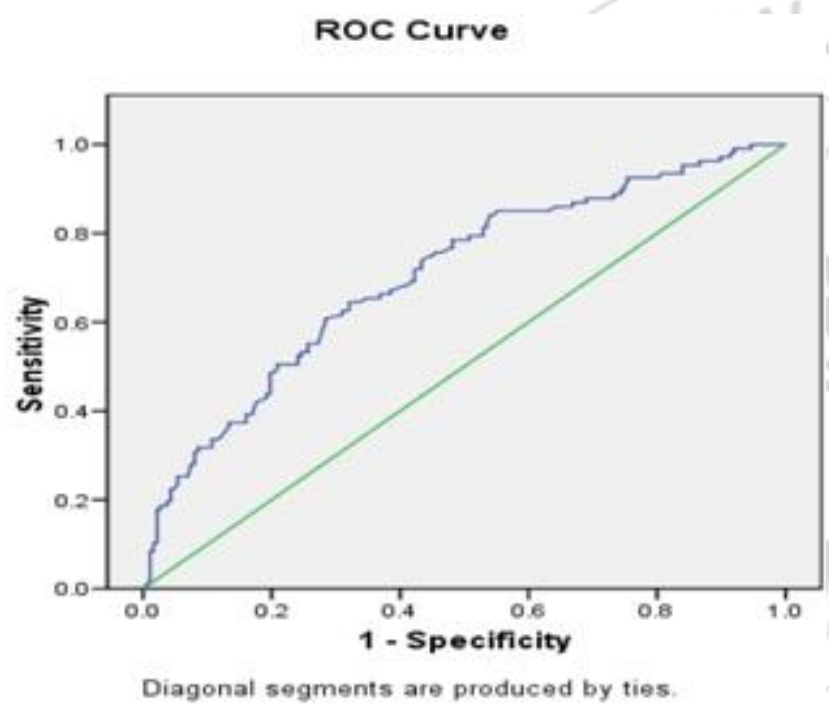

Figure 2: The cut off value of NLR above which there was a high risk of HCC development was $\geq 2.015$. AUC was $70.5 \%$, sensitivity was $60.7 \%$, specificity was $71.7 \%$, PPV of $55.1 \%$, NPV of $76.1 \%$, accuracy of $67.7 \%$ and positive LR of 2.14 .

Table 1: Baseline Patients Characteristics

\begin{tabular}{|c|c|c|c|c|}
\hline & Group & Mean & \begin{tabular}{|c|} 
Std. \\
Deviation \\
\end{tabular} & $\begin{array}{c}\mathrm{P} \\
\text { value. }\end{array}$ \\
\hline \multirow[b]{2}{*}{ Age } & HCC & 59.34 & 7.61 & \multirow{2}{*}{.000} \\
\hline & Non-HCC & 48.18 & 8.39 & \\
\hline \multirow[b]{2}{*}{ NLR } & HCC & 2.56 & 1.31 & \multirow{2}{*}{.000} \\
\hline & Non-HCC & 1.75 & .91 & \\
\hline \multirow{2}{*}{$\begin{array}{c}\text { WBCs }(\times 103 \\
\text { cells mm3) }\end{array}$} & HCC & 5870.37 & 3480.58 & \multirow{2}{*}{.887} \\
\hline & Non-HCC & 5823.92 & 2232.09 & \\
\hline \multirow[b]{2}{*}{ Child score } & HCC & 7.36 & 2.06 & \multirow{2}{*}{.000} \\
\hline & Non-HCC & 5.48 & 1.07 & \\
\hline \multirow{2}{*}{$\begin{array}{c}\text { ALT } \\
(0-41 \mathrm{U} / \mathrm{L})\end{array}$} & HCC & 62.00 & 59.27 & \multirow{2}{*}{.871} \\
\hline & Non-HCC & 62.90 & 38.64 & \\
\hline \multirow{2}{*}{$\begin{array}{c}\text { AST } \\
(0-37 \mathrm{U} / \mathrm{L})\end{array}$} & HCC & 88.48 & 83.07 & \multirow{2}{*}{.007} \\
\hline & Non-HCC & 64.99 & 41.06 & \\
\hline \multirow{2}{*}{$\begin{array}{l}\text { Albumin (3.5-5 } \\
\mathrm{g} / \mathrm{dl})\end{array}$} & HCC & 3.23 & .62 & \multirow[b]{2}{*}{.000} \\
\hline & Non-HCC & 3.94 & .57 & \\
\hline Platelet & HCC & 123.83 & 67.45 & \\
\hline
\end{tabular}

\begin{tabular}{|c|c|c|c|c|}
\hline \multirow{2}{*}{$(\times 103 / \mu \mathrm{l})$} & Non-HCC & 160.76 & 69.26 & .000 \\
\hline INR & HCC & 1.31 & .28 & \\
\cline { 2 - 4 } & Non-HCC & 1.11 & .16 & .000 \\
\hline \multirow{2}{*}{$\begin{array}{c}\text { Total bilirubin } \\
\text { (up to } 1 \mathrm{mg} / \mathrm{dl})\end{array}$} & HCC & 1.68 & 1.07 & \\
\cline { 1 - 4 } $\begin{array}{c}\text { Creatinine (up to } \\
1.2 \mathrm{mg} / \mathrm{dl})\end{array}$ & HCD & 1.01 & .57 & .000 \\
\cline { 2 - 4 } & Non-HCC & .93 & .28 & \\
\end{tabular}

$p>0.05$ (insignificant); $p<0.05$ (significant); $p<0.01$ (Highly significant)

\section{Discussion}

HCC is a major health problem in Egypt and represents the first cause of cancer related mortality (1).Chronic hepatitis C is the major risk factor of HCC in Egypt. Application of surveillance program to high risk populations is very important to diagnose HCC at early stages .The early diagnosis allows the application of curative therapies and improves patient outcome .The definition of population at highest risk, the surveillance method and frequency of its application is controversial. In EASL clinical practice guidelines, only abdominal ultrasonography(US) is recommended every six months in chronic HCV patients with liver fibrosis stage equal to or more than F3.US is applied every three months if a nodule smaller than one centimeter(cm) is encountered. Contrast enhanced abdominal CT is recommended every three to four months in previously ablated HCC patients. It is also used if abdominal ultrasonography is unreliable as in obese patients (18). In the Japanese clinical practice guidelines, they apply abdominal US and three tumor markers(AFP, PIVKAII, AFP L3) every three months with contrast enhanced abdominal CT or MRI examinations every six to twelve months (as an optional surveillance method) in extremely high risk chronic HCV(cirrhotic) patients. In high risk (chronic HCV) patients, abdominal US plus the three tumor markers every six months are recommended (20). 


\section{International Journal of Science and Research (IJSR) \\ ISSN (Online): 2319-7064 \\ Index Copernicus Value (2013): 6.14 | Impact Factor (2014): 5.611}

In the United States, only $12 \%$ of new HCV-related HCC cases are diagnosed through surveillance (21) and less than $20 \%$ of patients with cirrhosis who develop HCC have undergone regular surveillance (22).For this reason, it will be crucial to identify those who would benefit mostfrom continued surveillance. The addition of prediction method to surveillance programs may improve their cost-effectiveness by focusing on the extremely highriskgroups. Attempts to define patients who need a much closer follow up have been done. In Egypt, Yosry et al concluded that chronic HCV patients expressing fibroscan score $>25 \mathrm{k} \mathrm{Pa}$ are in need for meticulous follow up by imaging examinations(23). Ethoxibenzylmagnetic resonance imaging (EOB-MRI) was used to calculate the liver-intervertebral disc ratio (LI) as: (post-liver intensity/post-intervertebral disc intensity)/(pre-liver intensity/pre-intervertebral disc intensity).Nojiri et al concluded that $\mathrm{LI}<1.46$ was an independent factor that is associated with the risk of HCC occurrence in chronic hepatitis $\mathrm{C}$ patients and that LI may be a substitute for liver biopsy when evaluating this risk and its combined use with Fib-4 is a better predictive method of HCC progression (24).

High NLR significantly predicted poor overall survival (OS) of HCC patients irrespective of the treatment applied. Furthermore, high NLR also significantly correlated/with shortened disease free survival (DFS) of patient treated by liver transplantation or surgical resection. So, high NLR is closely associated with more aggressive phenotype of HCC with lower OS and DFS (25).

As regards the epidemiological features of the study patients, males represented $90.1 \%$ and females represented $9.9 \%$ in group I with strong male predominance, while in group II males represented $57.7 \%$ and females represented $42.3 \%$.The mean age of patients in HCC group(groupI)was 59.34 \pm 7.61 years while it was $48.18 \pm 8.39$ in group II with highly significant older age in HCC group $(\mathrm{P} \leq .000)$.

As regards the hepatic condition as evaluated by Child-Pugh score, Child class A represented 43.2\%, Child class B represented $42.3 \%$ while Child class $\mathrm{C}$ represented $14.4 \%$ in group I. In group II, Child class A represented $89.5 \%$, Child class B represented $8.6 \%$ while Child class C represented $1.8 \%$.As regards the tumor burden in group I, the tumor size was smaller than $2 \mathrm{~cm}$ in $9 \%, 2-3 \mathrm{~cm}$ in $11.7 \%$ and larger than $3 \mathrm{~cm}$ in $79.3 \%$.The tumor wasunifocal in $33.3 \%$, multifocal in $63.1 \%$ and diffuse in 3.6\%(figure 1).Meantumor size was $5.56 \pm 2.1 \mathrm{~cm}$. The smallest tumor diagnosed non invasively was $1.3 \mathrm{~cm}$. The distribution of Seventh edition TNM tumor stage (26) in group I was as follows: stage I represented $19.3 \%$, stage II represented $25.5 \%$, stage IIIa represented $19.3 \%$, stage IIIb represented $18.3 \%$, stage IIIc represented $1 \%$, stage IVa represented $8 \%$ and stage IVb represented 7\%. These results were obtained after adherence to the surveillance programme as recommended by EASL guidelines and indicate the need for more meticulous follow up in some patients.
NLR was significantly higher in group I than group 2 .It was $2.56 \pm 1.31$ in group I versus $1.75 \pm .91$ in group II $(\mathrm{P} \leq 000)$. Using ROC curve, the cut off value of NLR above which there was a high risk of HCC occurrence was $\geq 2.015$. Area under the curve (AUC) was 70.5\%, sensitivity was $60.7 \%$, specificity was $71.7 \%$, positive predictive value of $55.1 \%$, negative predictive value of $76.1 \%$, accuracy of $67.7 \%$ and positive likelihood ratio of 2.14. In clinical practice, however NLR will not be used as a diagnostic test of HCC, but used as an indicator of the risk of HCC. In this aspect, SSLR is better than a fixed cutoff value (23). The SSLR for HCC presence by NLR was 0.54 if NLR $<2,1.74$ if NLR was 2 to 4 and 7.14 if NLR was $>4$. This means that NLR $>4$ is 7.14 times more likely to occur in CHC patients with HCC than CHC patients without HCC. So, CHC patients expressing NLR $>4$ are in need for much closer follow up for earlier detection of HCC.

\section{Conclusion}

Neutrophil lymphocyte ratio(NLR) could be used as a predictor of HCC occurrence in chronic HCV Egyptian patients .Chronic HCV patients expressing NLR $>4$ are in need for much closer follow up.

\section{References}

[1] Anwar WA, Khaled HM, Amra HA, El-Nezami H, Loffredo CA. Changing pattern of hepatocellular carcinoma (HCC) and its risk factors in Egypt: Possibilities for prevention.Mutation Research 2008; 659: 176-184

[2] Egyptian national control strategy for viral hepatitis, 2008-2012 Arab Republic of Egypt, Ministry of Health and Population, National Committee for the Control of Viral Hepatitis.

[3] Proctor MJ, Talwar D, Balmar SM, et al : The relationship between the presence and site of cancer, an inflammationbased prognostic score and biochemical parameters. Initial results of the Glasgow Inflammation Outcome Study.Br J Cancer 2010, 103:870-876.

[4] Balkwill F, Mantovani A: Inflammation and cancer: back to Virchow? Lancet 2001, 357:539-545.

[5] Jaiswal M, LaRusso NF, Burgart LJ, et al : Inflammatory cytokines induce DNA damage and inhibit DNA repair in cholangiocarcinoma cells by a nitric oxide-dependent mechanism. Cancer Res 2000, 60:184-190.

[6] McMillan DC, Canna K, McArdle CS: Systemic inflammatory response predicts survival following curative resection of colorectal cancer. Br J Surg 2003, 90:215-219.

[7] Hashimoto K, Ikeda Y, Korenaga D, et al: The impact of preoperative serum C-reactive protein on the prognosis of patients with hepatocellular carcinoma.Cancer 2001, 103:1856-1864.1.

[8] Zahorec R: Ratio of neutrophil to lymphocyte countsrapid and simple parameter of systemic inflammation and stress in critically ill. Bratisl Lek Listy 2001, 102:5-14. 


\section{International Journal of Science and Research (IJSR) \\ ISSN (Online): 2319-7064 \\ Index Copernicus Value (2013): 6.14 | Impact Factor (2014): 5.611}

[9] McCourt M, Wang JH, Sookhai S, Redmond HP. Proinflammatory mediators stimulate neutrophildirected angiogenesis. Arch Surg. 1999;134(12):1325-1331; discussion 1331-1322.

[10]Di Carlo E, Forni G, Musiani P. Neutrophils in the antitumoral immune response. Chem Immunol Allergy. 2003;83:182- 203.

[11] McCourt M, Wang JH, Sookhai S, Redmond HP. Activated human neutrophils release hepatocyte growth factor/scatter factor. Eur J Surg Oncol. 2001;27(4):396403.

[12] Jablonska E, Kiluk M, Markiewicz W, et al. TNFalpha, IL6 and their soluble receptor serum levels and secretion by neutrophils in cancer patients. Arch Immunol Ther Exp (Warsz). 2001;49(1):63-69.

[13] Schaider H, Oka M, Bogenrieder T, et al. Differential response of primary and metastatic melanomas to neutrophils attracted by IL8. Int J Cancer. 2003;103(3):335-343.

[14] Shamamian P, Schwartz JD, Pocock BJ, et al. Activation of progelatinase A (MMP2) by neutrophil elastase, cathepsin G, and proteinase3: a role for inflammatory cells in tumor invasion and angiogenesis. J Cell Physiol. 2001;189(2):197- 206.

[15] Scapini P, Nesi L, Morini M, et al. Generation of biologically active angiostatin kringle $1-3$ by activated human neutrophils. J Immunol. 2002;168(11):5798-5804.

[16] Petrie HT, Klassen LW, Kay HD. Inhibition of human cytotoxic $\mathrm{T}$ lymphocyte activity in vitro by autologous peripheral blood granulocytes. J Immunol. 1985;134(1):230-234.

[17]ElHag A, Clark RA. Immunosuppression by activated human neutrophils. Dependence on the myeloperoxidase system. J Immunol. 1987;139(7):2406-2413.

[18]European Association for the Study of the Liver, European Organization for Research and Treatment of Cancer. EASL-EORTC Clinical Practice Guidelines: Management of hepatocellular carcinoma. Journal of Hepatology 2012 vol. 56 j 908-943

[19] Beck JR.Likelihood ratios.Another enhancement of sensitivity and specificity. Arch Pathol Lab Med 1986; 110: 685-686.

[20] Masatoshi Kudo, Kwang Hyub Han, Norihiro Kokudo, et al. Liver Cancer Working Group Report. Jpn J Clin Oncol 2010; 40 (Supplement 1) i19-i27

[21] Davila JA, Henderson L, Kramer JR, et al. Utilization of surveillance for hepatocellular carcinoma among hepatitis $C$ virus-infected veterans in the United States. Ann Intern Med. 2011;154:85-93.

[22] Davila JA,Morgan RO, Richardson PA, Du XL, McGlynn KA, El-Serag HB. Use of surveillance for hepatocellular carcinoma among patients with cirrhosis in the United States. Hepatology. 2010;52:132-141.

[23] Ayman Yosry, Rabab Fouad, Hanan Abdel Hafez, et al. Transient Elastography can Predict the Risk of Hepatocellular Carcinoma in Egyptian Patients with Chronic Hepatitis. Journal of GHR 2013 July 21 2(7): 687-691

Paper ID: NOV162165
[24] Shunsuke Nojiri, Kei Fujiwara, Noboru Shinkai, et al. Evaluation of hepatocellular carcinoma development in patients with chronic hepatitis C by EOB-MRI. World $J$ Hepatol 2014 December 27; 6(12): 930-938

[25] Wei-Kai Xiao†, Dong Chen†, Shao-Qiang Li, et al. Prognostic significance of neutrophil-lymphocyte ratio in hepatocellular carcinoma: a meta-analysis. BMC Cancer 2014, 14:117

[26] Somasundaram Subramaniam1, Robin K. Kelley and Alan P. Venook.A review of hepatocellular carcinoma (HCC) staging systems. Chin Clin Oncol 2013;2 (4):33

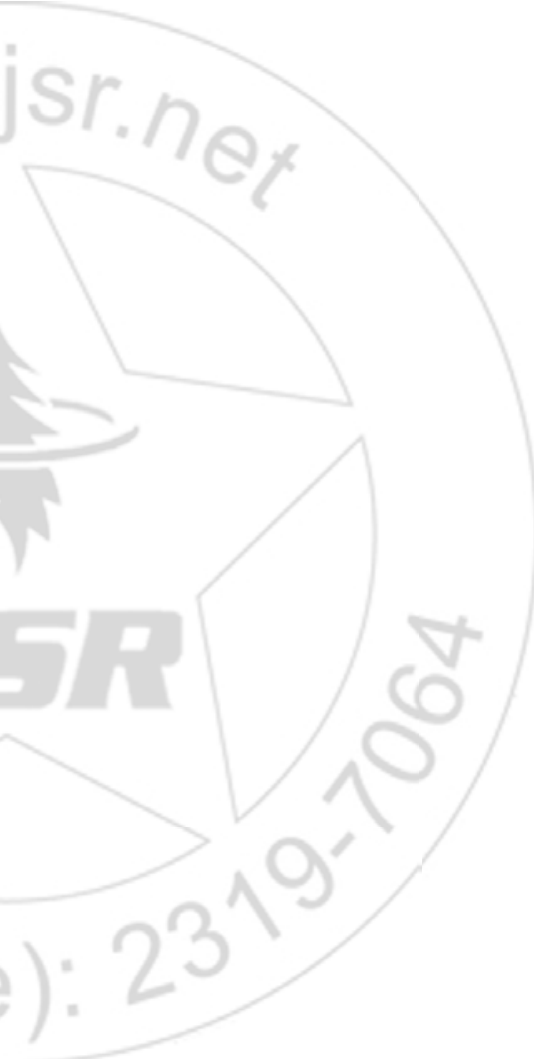

